\title{
EXTENDED SYNTHETIC APERTURE FOCUSING TECHNIQUE FOR ULTRASONIC IMAGING OF CONCRETE
}

\author{
Dr. Kyle Hoegh and Professor Lev Khazanovich $_{\mathrm{a}}$ \\ aUniversity of Minnesota Department of Civil, Environmental, and Geo- Engineering \\ 500 Pillsbury Drive S.E. | Minneapolis, MN, USA 55455-0116
}

Dr. Hoegh (corresponding author) contact details - email: hoeg0021@umn.edu phone: +1-612-626-4098

Professor Khazanovich contact details: - email: khaza001@umn.edu phone: +1-612-624-4764

\begin{abstract}
Quantitative nondestructive characterization of defects and inclusions in portland cement concrete structures are realized in this paper via extended reconstructions for linear array ultrasound systems. This is accomplished through generalization of traditional Kirchhoff -based synthetic aperture focusing technique migration to mitigate the effects of limited aperture and handle multiple scans as a single virtual array with increased effective aperture. Pearson's correlation is utilized to account for uncertainty in relative position of individual measurement and mitigate the need for robotic precision when placing adjacent scans. The robustness of the method is demonstrated on artificially generated data as well as in-situ measurements for assessment of internal portland cement concrete characteristics such as inclusions and cracks.
\end{abstract}

Keywords: concrete, ultrasound, array, SAFT, imaging 


\section{$1 \quad 1$ INTRODUCTION}

2 There is a longstanding interest in nondestructive characterization of portland cement concrete

3 (PCC) structures, which comprise a significant portion of civil infrastructure [1]. Active elastic

4 wave-based methods, such as impact-echo and ultrasound have been used with varied success for

5 these applications. For example, conventional impact echo is capable of detecting planar layer

6 interfaces [2-4]. Further advancements such as air coupled impact-echo have allowed for more

7 convenient and productive measurements and multiple measurement pairs [5-10]. Dry-point

8 contact (DPC) low-frequency $(\sim 50 \mathrm{kHz})$ shear wave ultrasonic transducers have been shown to

9 mitigate issues with signal variability and sensor positional shift instability [11-13]. Various

10 versions of self-contained DPC pulse-echo arrangements of these transducers have been

11 successfully used for characterization of civil engineering materials [14-18].

13 In addition to hardware improvements, significant progress has been made in the data processing

14 and interpretation. Traditional A- and B-scan analysis has been improved through the

15 introduction of Kirchhoff-based migration techniques, most notably the synthetic aperture

16 focusing technique (SAFT) [19-21]. However, there are limitations in analysis of some

17 important practical problems due to effects of limited aperture within each self-contained scan

18 [22, 23]. A major factor in this effect is the dependence of the reflectivity within each

19 reconstruction on the relative position below the self-contained device, interfering with the

20 ability to characterize changes in reflectivity within the region of interest (ROI) of the evaluated

21 structure. As explained by Shokouhi et al. (2014), the limited aperture can create situations

22 where "measurements may be inconclusive if the array is located directly above an edge of a

23 defect [23]." These effects, where the magnitude of reflection is affected by the position relative

24 to the aperture and not on the characteristics of interest, can cause misinterpretations.

26 In this paper, the effect of limited aperture is addressed through generalization of the

27 reconstruction process using overlapping measurements. This creates an effective virtual

28 aperture that is adaptable to the desired region of interest (ROI). The method is also shown to

29 account for uncertainty in the measurement process to eliminate the need for robotic precision.

30 The feasibility and effectiveness of the proposed method for detection of various internal 
31 concrete characteristics is evaluated using artificially generated data and measurements of in-situ

32 concrete structures.

\section{$33 \quad 2$ METHOD}

\section{$34 \quad 2.1$ Equipment and Data}

35 While the method presented in this paper can be used in conjunction with other linear array

36 systems and testing mediums, the data collected herein were from various PCC structures with a

37 specific linear array device with emitting and receiving DPC transducer pairs at set spacing [11,

38 15, 24]. This data was used to demonstrate the capability of the proposed extended

39 reconstruction method for evaluation of PCC structures. The data from each scan consists of

40 multiple transmitting and receiving impulse time-history measurements. Figure 1 shows a

41 simple schematic of a PCC slab on a reflecting interface to illustrate the arrangement of the

42 testing equipment and a typical impulse time-history response. Figure 1a shows a schematic of

43 emitting and receiving transducer locations as well as supplementary information describing the

44 type of response evaluated in this study. While a simple schematic of all measurement pairs is

45 denoted with gray lines, a $200 \mathrm{~mm}$ spaced transducer pair location is highlighted in black. For

46 this pair, the travel path for a direct shear wave arrival as well as the round-trip travel path

47 reflecting at the depth of the PCC slab thickness "backwall" is shown. Figure 1b shows the

48 corresponding impulse time-history of a scan on an approximately $300 \mathrm{~mm}$ thick PCC pavement

49 [25]. A peak in magnitude of the response at the receiving transducer can be observed at the

50 time associated with the shear wave direct arrival as well as the backwall reflection caused by a

51 change in acoustic impedance at the depth of the PCC slab. 


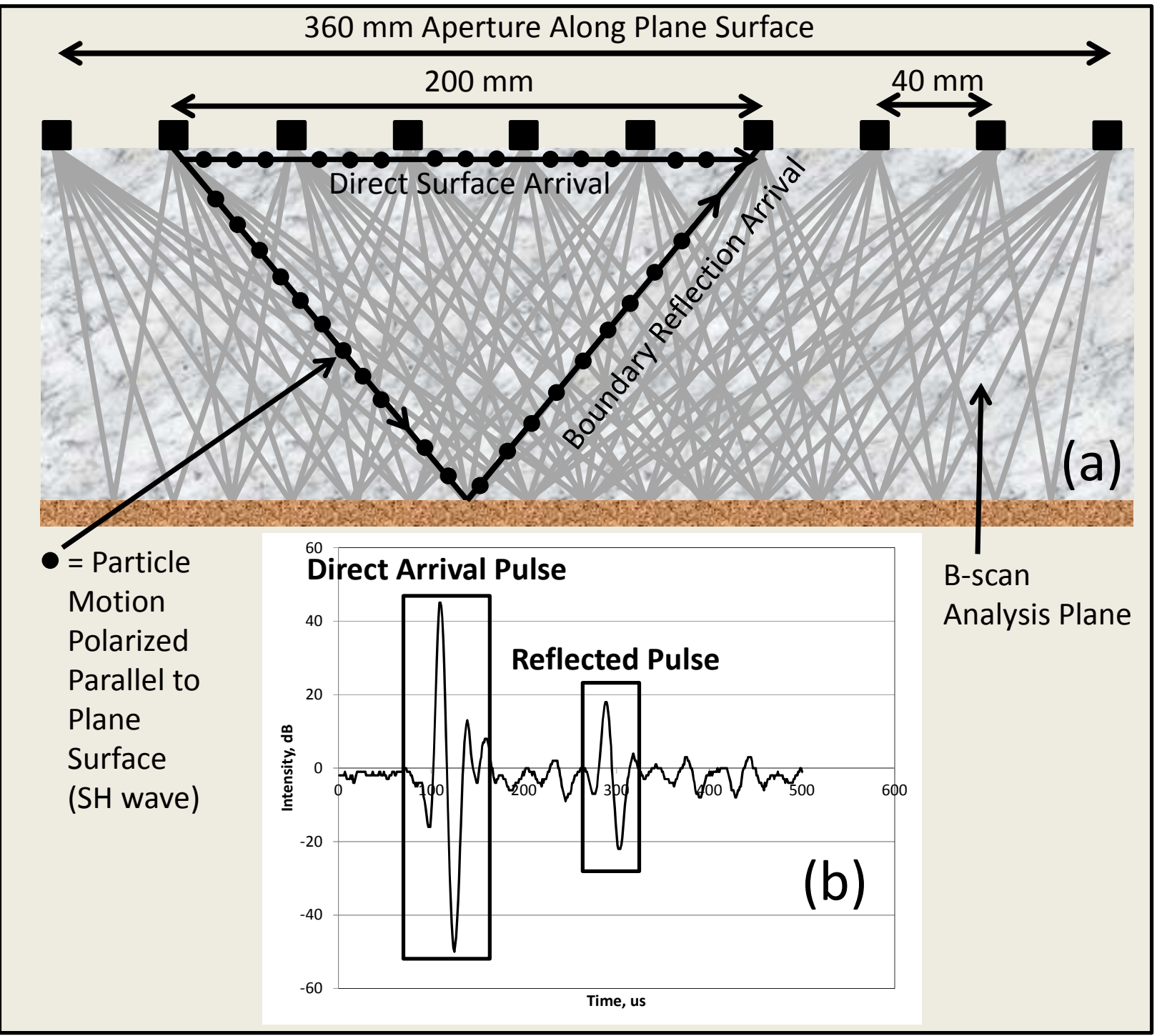

Figure 1: Illustration of the type of data utilized in this paper including a [a] schematic of the measurement setup on a concrete slab including direct and reflection arrival paths and [b] example impulse time history from a transducer pair spaced by $200 \mathrm{~mm}$.

59 To describe the linear array system, let it have $\mathrm{T}$ transducers equally spaced at $\Delta \mathrm{x}$, and numbered

60 from left to right where transducers from 1 to $\mathrm{T}-1$ are emitting and from 2 to $\mathrm{T}$ are receiving.

61 Figure 2 shows an example linear array setup with $\mathrm{x}_{1}^{\prime}$ being the leftmost transducer channel.

62 The leftmost emitting transducer is located at the leftmost transducer location, $\mathrm{x}_{\mathrm{e} 1}^{\prime}=\mathrm{x}_{1}^{\prime}$, leftmost

63 receiving transducer is located adjacent to the leftmost emitting transducer $\mathrm{x}_{\mathrm{r} 1}^{\prime}=\mathrm{x}_{\mathrm{e} 1}^{\prime}+\Delta \mathrm{x}=$ 
$64 \mathrm{x}_{\mathrm{e} 1+1}^{\prime}$, rightmost receiving transducer is located at the rightmost transducer location $\mathrm{x}_{\mathrm{R}}^{\prime}=\mathrm{x}_{\mathrm{T}}^{\prime}$,

65 and rightmost emitting transducer is located adjacent to the rightmost receiving transducer

66 location $\mathrm{x}_{\mathrm{E}}^{\prime}=\mathrm{x}_{\mathrm{R}}^{\prime}-\Delta \mathrm{x}=\mathrm{x}_{\mathrm{T}-1}^{\prime}$.

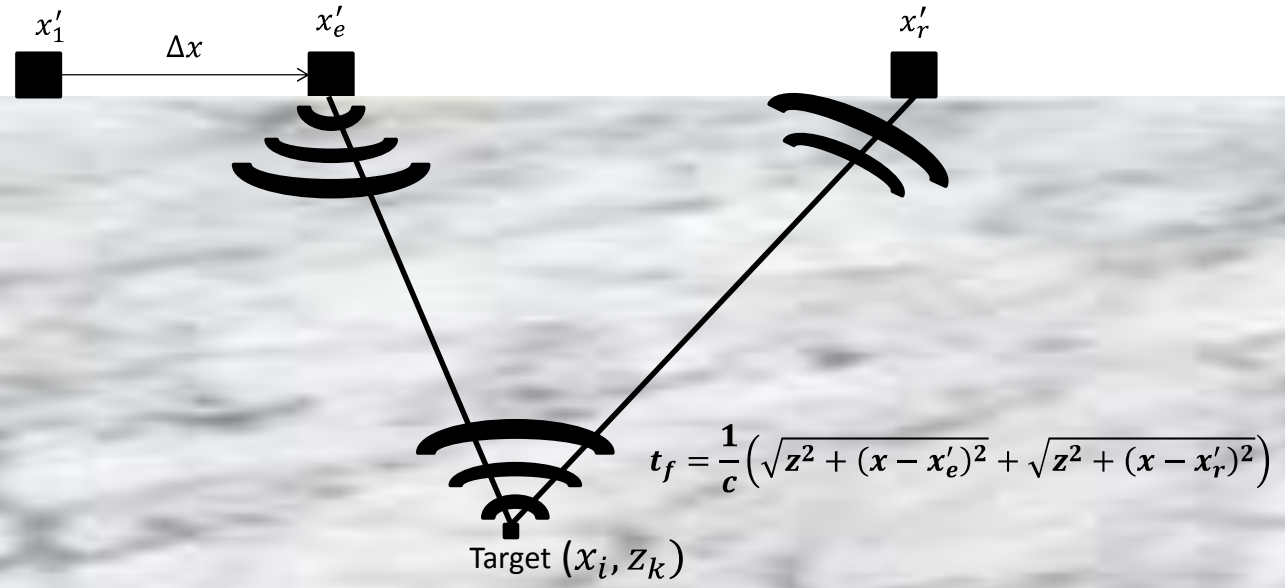

Figure 2: Linear array representation.

The measured signals for the setup in this study have $\mathrm{T}=10$ transducer channel locations at $\Delta \mathbf{x}=40 \mathrm{~mm}$ spacing covering a lateral device aperture of $360 \mathrm{~mm}$ in each reconstruction. Each channel is comprised of a group of 4 transducer elements where the directivity of the wear tip oscillations are controlled by the phase of parallel piezoelectric elements in each transducer. Each group of 4 transducer elements are designed to produce shear horizontal (SH) waves focused to a plane perpendicular to the surface and centered between the set of 4 transducer elements [11]. Each group of 4 transducer elements can be treated as one channel where the $\mathrm{SH}$ wave is polarized parallel to the plane surface of the tested specimen in each self-contained array scan. This allows for 45 sending and receiving pairs operating at a nominal frequency of $50 \mathrm{KHz}$ with a sufficiently short impulse. Figure 1 shows that the direction of particle motion is out of the plane with respect to the evaluated cross-section which is denoted using the convention from Krautktamer et al. with a black dot indicating the polarization [26]. In this case, the particle motion is into and out of the evaluated B-scan plane and is always parallel to the reflecting object, regardless of the pairs used or shape of the inclusion. Along this plane, the SH wave

83 reflection amplitude does not depend on the angle of incidence with no mode change occurring 84 [26]. This mitigates ghost images in the SAFT reconstruction and simplifies analysis. Although 85 not a subject of this paper, it should be noted that mode conversions can be used to extract 
additional information and has potential to account for phenomenon other than SH-wave

87 interactions of interest in this study [27].

\subsection{Reconstruction Principle}

90 The synthetic aperture focusing technique (SAFT) has shown to be an effective migration

91 heuristic to create focused reconstructions for space domain analysis after assuming or

92 calculating an approximate velocity and system delay [27-30]. This is often applied along a

93 single analysis axis with each measurement from unique emitting/receiving pair locations or

94 along a plane with multiple measurements in set shift factors from a single emitting/receiving

95 location [31-33]. Using the setup in this study, the general SAFT is formalized to allow for

96 interpretation of signals with sending and receiving transducers located at different locations and

97 to allow for a signal sent from one location to be received at various locations along the surface

98 [34-35]. The shear wave direct arrivals from each measurement pair can be used to calculate the

99 approximate shear wave velocity and system delay related shift factor in a similar manner to that

100 described by Blum et al. (1997) [36]. Using these input values and summing over all possible

101 transducer pair locations at discrete points produces a reconstructed image referred to as a SAFT

102 B-scan. Since this is the basis of the proposed method, it is formalized here to provide context.

103 Equations 1 and 2 show the relationships used to create SAFT B-scans for the ultrasonic linear

104 array in this study:

105

$\hat{\mathrm{o}}_{\mathrm{i}, \mathrm{k}}=\sum_{\mathrm{e}=1}^{\mathrm{T}-1} \sum_{\mathrm{r}=\mathrm{e}+1}^{\mathrm{T}} \mathrm{A}\left(\mathrm{x}_{\mathrm{r}}^{\prime}, \mathrm{x}_{\mathrm{e}}^{\prime}, \mathrm{x}_{\mathrm{i}}, \mathrm{z}_{\mathrm{k}}\right) \Psi_{\mathrm{e}, \mathrm{r}}\left(\mathrm{x}_{\mathrm{i}}, \mathrm{z}_{\mathrm{k}}\right)$

$106 \Psi_{\mathrm{e}, \mathrm{r}}\left(\mathrm{x}_{\mathrm{i}}, \mathrm{z}_{\mathrm{k}}\right)=\mathrm{s}\left(\mathrm{x}_{\mathrm{r}}^{\prime}, \mathrm{x}_{\mathrm{e}}^{\prime}, \frac{1}{\mathrm{c}}\left(\sqrt{\mathrm{z}_{\mathrm{k}}^{2}+\left(\mathrm{x}_{\mathrm{i}}-\mathrm{x}_{\mathrm{e}}^{\prime}\right)^{2}}+\sqrt{\mathrm{z}_{\mathrm{k}}^{2}+\left(\mathrm{x}_{\mathrm{i}}-\mathrm{x}_{\mathrm{r}}^{\prime}\right)^{2}}\right)\right)$

107 where $\hat{\mathrm{o}}_{\mathrm{i}, \mathrm{k}}$ is the response assigned to each position within the ROI; $\mathrm{i}$ and $\mathrm{k}$ are the indexes for

108 the horizontal and vertical positions of the ROI, respectively, which is represented by a W $\times \mathrm{D}$

109 set of points located in $\mathrm{W}$ columns, and D rows; $\mathrm{T}$ is the number of transducer channel locations;

$110 \mathrm{e}$ and $\mathrm{r}$ are the indexes for the emitting and receiving transducers; and $\mathrm{s}$ is the magnitude of the

111 response at the evaluated time of flight for given transducer transducers pair locations, $\mathrm{x}_{\mathrm{r}}^{\prime}$ and

$112 \mathrm{x}_{\mathrm{e}}^{\prime}$. The apodization coefficient, A, accounts for factors such as the incident angle and other

113 traits of the signal and tested medium [37]. 
115 By analyzing changes in instantaneous amplitude within the ROI, locations of changes in

116 acoustic impedance, and associated changes in reflectivity, can be identified [25]. The Hilbert

117 transform can be applied to calculate instantaneous attributes of a time series, especially the

118 amplitude and frequency [38, 39]. The Hilbert transform, $\Upsilon(\mathrm{z})$, of a given function, $\chi(\mathrm{z})$, is

119 defined by the following equation:

$120 \quad \Upsilon(\mathrm{z})=\frac{1}{\pi} \mathrm{P} \int_{-\infty}^{\infty} \frac{\chi(\mathrm{s})}{\mathrm{z}-\mathrm{s}} \mathrm{ds}$

121 where $\mathrm{P}$ is the principal value of the singular integral in equation 3 and the complex analytic

122 signal, $\mathrm{Z}(\mathrm{z})$, is given by:

$123 \mathrm{Z}(\mathrm{z})=\chi(\mathrm{z})+\mathrm{j} \Upsilon(\mathrm{z})$

124

125 In this case, the absolute value of the complex signal, $\mathrm{Z}$, is calculated at each horizontal

126 coordinate of the SAFT reconstruction to give the instantaneous amplitude as follows:

$127 \hat{\mathrm{o}}^{\mathrm{IA}}(\mathrm{x}, \mathrm{z})=\sqrt{(\hat{\mathrm{o}}(\mathrm{x}, \mathrm{z}))^{2}+\left(\frac{\mathrm{P}}{\pi} \int_{-\infty}^{\infty} \frac{\widehat{o}(\mathrm{x}, \mathrm{s})}{\mathrm{z}-\mathrm{s}} \mathrm{ds}\right)^{2}}$

128 where the relative reflectivity, $\hat{o}^{\mathrm{IA}}(\mathrm{x}, \mathrm{z})$, defines the instantaneous amplitude-based SAFT

129 reconstruction and $\mathrm{P}$ is the principal value of the singular integral. Since the ROI is represented

130 by a $\mathrm{W} \times \mathrm{D}$ set of points located in $\mathrm{W}$ columns, and $\mathrm{D}$ rows, the following matrix formalization

131 can be used to represent SAFT-IA reconstructed image, $[\widehat{\mathrm{O}}]^{\mathrm{IA}}$ :

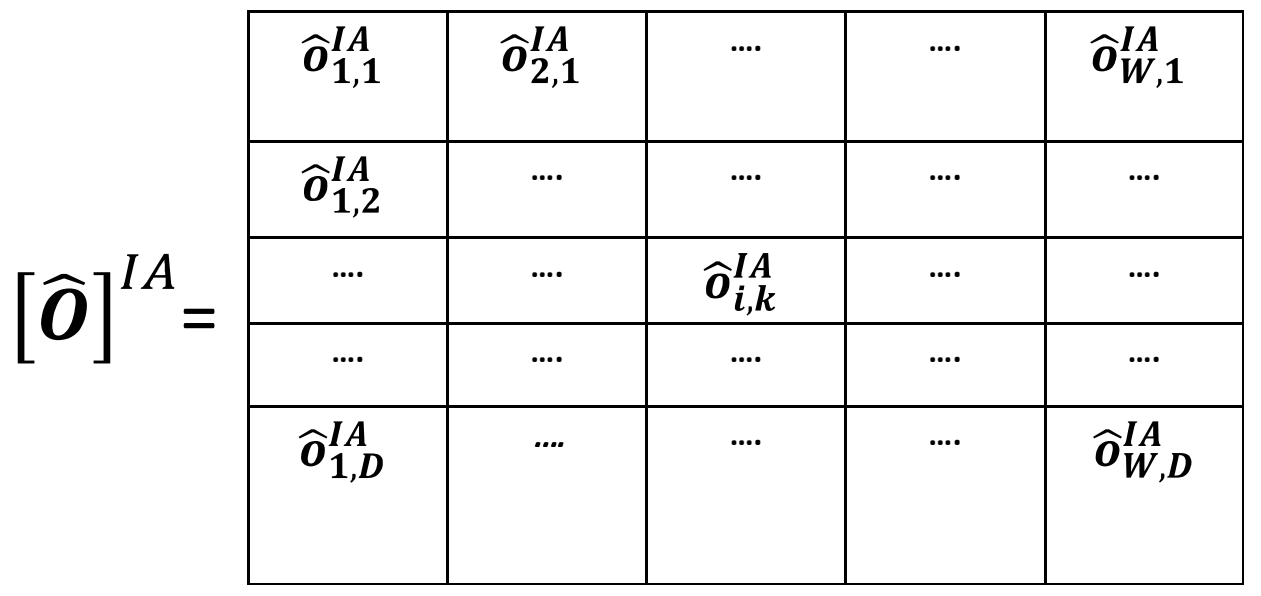

134 For the ultrasonic linear array used in this study the following apodization factor was found to

135 improve the reconstruction resolution:

136

$\mathrm{A}\left(\mathrm{x}_{\mathrm{r}}^{\prime}, \mathrm{x}_{\mathrm{e}}^{\prime}, \mathrm{x}_{\mathrm{i}}, \mathrm{z}_{\mathrm{k}}\right)=\alpha_{\mathrm{e}}\left(\mathrm{x}_{\mathrm{e}}^{\prime}, \mathrm{x}_{\mathrm{i}}, \mathrm{z}_{\mathrm{k}}\right) * \alpha_{\mathrm{r}}\left(\mathrm{x}_{\mathrm{r}}^{\prime}, \mathrm{x}_{\mathrm{i}}, \mathrm{z}_{\mathrm{k}}\right)$ 
137 where:

$$
\alpha_{\mathrm{e}}\left(\mathrm{x}_{\mathrm{e}}^{\prime}, \mathrm{x}_{\mathrm{i}}, \mathrm{z}_{\mathrm{k}}\right)=\frac{\mathrm{z}_{\mathrm{k}}}{\sqrt{\left(\mathrm{x}_{\mathrm{i}}-\mathrm{x}_{\mathrm{e}}^{\prime}\right)^{2}+\mathrm{z}_{\mathrm{k}}^{2}}}
$$

138

$$
\alpha_{\mathrm{r}}\left(\mathrm{x}_{\mathrm{e}}^{\prime}, \mathrm{x}_{\mathrm{i}}, \mathrm{z}_{\mathrm{k}}\right)=\frac{\mathrm{z}_{\mathrm{k}}}{\sqrt{\left(\mathrm{x}_{\mathrm{i}}-\mathrm{x}_{\mathrm{r}}^{\prime}\right)^{2}+\mathrm{z}_{\mathrm{k}}^{2}}}
$$

139

140 The above formulation allows for reconstruction from a self-contained array system where each

141 element may act as both a sender and receiver. For an equally spaced transducer array, such as

142 that used in this study, this results in higher energy radiation content towards the center of the

143 reconstruction leading to the effect of limited aperture. It is proposed to address this issue by

144 taking multiple overlapping measurements and combining them into a single panoramic

145 reconstruction using the formulations presented in the subsection 2.3.

\section{$146 \quad$ 2.3 SAFT Panoramic}

147 Consider a set of array measurements taken at prescribed shifts in the direction along the

148 aperture of the linear array. Each prescribed shift is within the aperture of the previous scan. For

149 each of these measurements, a SAFT-IA B-scan, is obtained using the procedure described in

150 subsection 2.2. In the proposed implementation, each individual SAFT-IA B-scan, $\widehat{\mathrm{O}}_{\mathrm{k}, \mathrm{i}}^{\mathrm{m}}$ is

151 sequentially converted to the dimensions of the larger region of interest, $\mathrm{ROI}_{\mathrm{PAN}}$, where $\mathrm{m}$ is an

152 index of the current SAFT-IA B-scan. The vertical dimensions of the new ROI ${ }_{\text {PAN }}$ and ROI of

153 each SAFT-IA B-scan $\widehat{\mathrm{O}}_{\mathrm{k}, \mathrm{i}}^{\mathrm{m}}$ are the same while the horizontal dimensions are increased. Let the

154 leftmost (lowest) horizontal coordinates of the m-th SAFT-IA B-scan, $\mathrm{x}_{1}$, correspond to the $\mathrm{x}_{\mathrm{i}^{*}}$

155 coordinate within the panoramic reconstruction (SAFT-Pan). In this case all intensity values of

156 the original SAFT-IA B-scan within the new ROI ${ }_{\text {PAN }}$ are placed according to their physical

157 location with zeros padding any location where no intensity value applies. Each padded SAFT

$158 \mathrm{~B}$-scan, $\widehat{\mathrm{O}}_{\mathrm{k}, \mathrm{i}}^{\mathrm{PAN}, \mathrm{m}}$, is created according to the following relationship for all $\widehat{\mathrm{O}}_{\mathrm{k}, \mathrm{i}}^{\mathrm{m}}$ horizontal positions

159 within the ROI ${ }_{\text {PAN }}$ :

$160 \widehat{\mathrm{O}}_{\mathrm{k}, \mathrm{i}}^{\mathrm{PAN}, \mathrm{m}}=\widehat{\mathrm{O}}_{\mathrm{k}, \mathrm{i}-\mathrm{i}^{*}+1}^{\mathrm{m}}$ for $\mathrm{i}^{*} \leq \mathrm{i} \leq \mathrm{i}^{*}+\mathrm{W}-1$

$161 \widehat{\mathrm{O}}_{\mathrm{k}, \mathrm{i}}^{\mathrm{PAN}, \mathrm{m}}=0$ for $\mathrm{i}<\mathrm{i}^{*}$ or $\mathrm{i} \geq \mathrm{i}^{*}+\mathrm{W}$ 
163 Equation 9 shows the matrix representation of an example panoramic form, $[\widehat{0}]^{\mathrm{PAN}, \mathrm{m}}$, of the $\mathrm{m}-$ 164 th applied SAFT-IA B-scan.

\begin{tabular}{|c|c|c|c|c|c|c|c|}
\hline \multirow{4}{*}[\widehat{\boldsymbol{O}}]{$^{P A N, m}=$} & $\mathbf{0}$ & $\mathbf{0}$ & $\widehat{\boldsymbol{o}}_{\boldsymbol{i}^{*}, \mathbf{1}}^{P A N, M}$ & $\ldots$ & $\begin{array}{l}P A N, M \\
i^{*}+W-1,1\end{array}$ & $\mathbf{0}$ & 0 \\
\hline & 0 & 0 & $\ldots$ & $\widehat{\boldsymbol{\sigma}}_{i, k}^{P A N, M}$ & $\ldots$ & 0 & 0 \\
\hline & $\mathbf{0}$ & $\mathbf{0}$ & $\ldots$ & $\ldots$. & $\ldots$ & $\mathbf{0}$ & 0 \\
\hline & 0 & 0 & $\widehat{\boldsymbol{o}}_{i^{*}, D}^{P A N, M}$ & $\ldots$ & $\widehat{\boldsymbol{o}}_{W, D}^{P A N, M}$ & 0 & 0 \\
\hline
\end{tabular}

168 After this procedure the individual scans can be combined into a single panoramic

169 representation, SAFT-Pan, using the following rule:

$170 \widehat{\mathrm{O}}_{\mathrm{k}, \mathrm{i}}^{\mathrm{PAN}}=\max _{\mathrm{m}}^{\max }\left(\widehat{\mathrm{O}}_{\mathrm{k}, \mathrm{i}}^{\mathrm{PAN}, \mathrm{m}}\right)$ for all $\mathrm{k}$ and $\mathrm{i}$ in the $\mathrm{ROI}_{\mathrm{PAN}}$, where $[\widehat{\mathrm{O}}]^{\mathrm{PAN}}$ is the matrix form of the 171 SAFT-Pan.

172

173 To illustrate the use of SAFT-Panoramic extended reconstructions, consider a reinforced

174 concrete pavement on grade. Figure 3 shows the cross section of the tested location comprised 175 of two $38 \mathrm{~mm}$ diameter steel reinforcements embedded in a $300 \mathrm{~mm}$ thick portland cement 176 concrete (PCC) slab. This is the cross sectional location and dimensions for the analysis and 177 reconstructions presented in Figure 4, Figure 5, Figure 6, and Figure 10.

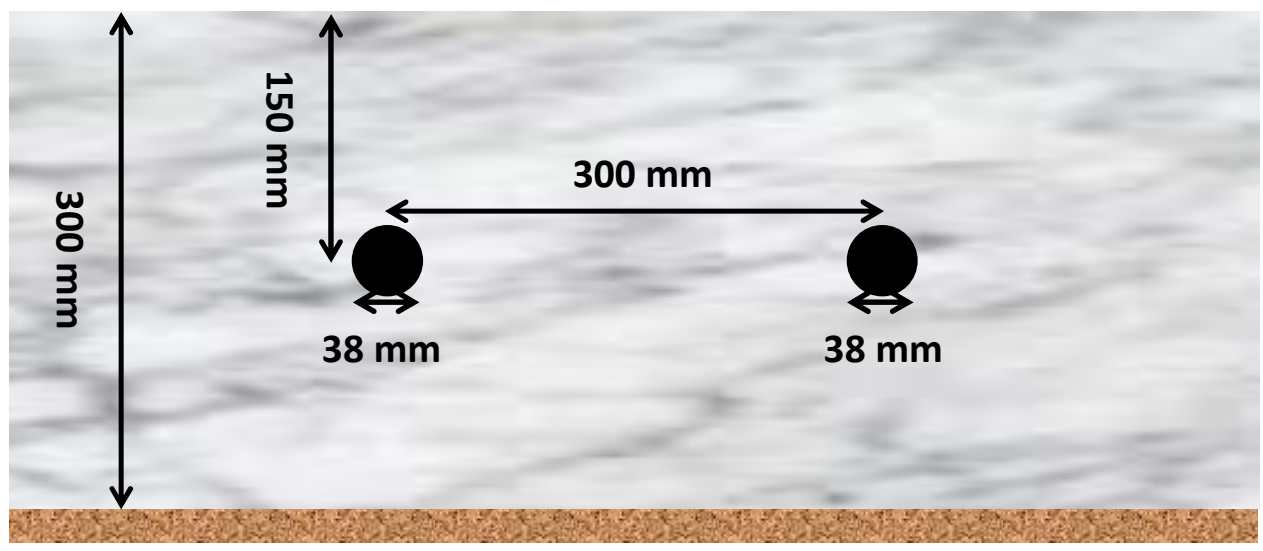

Figure 3. Schematic of the reinforced concrete structure used for analysis. 
181 A set of 9 scans were completed by placing the DPC transducer array on the concrete surface

182 starting on the left side of the cross-section shown in Figure 3 and moving to the right in $50 \mathrm{~mm}$

183 target shift factors with each increasing scan. Figure 4 shows three representative SAFT-IA B-

184 scans, labeled (a), (b), and (c), corresponding to the lateral locations with the same labels also

185 shown in Figure 4. The presence of a laterally oblong high intensity reflection (white) can be

186 observed the bottom of each reconstruction. This backwall reflection corresponds to the PCC

187 slab thickness. Presence of round high intensity (white) reflections indicates the existence of the

188 metal inclusions at the mid-depth of the PCC slab.

190 Further analysis of Figure 4 indicates that the reconstructions only partially describe the physical

191 reality. For example, the PCC slab depth interface high intensity reflection does not extend

192 throughout the width of each scan to match the physical interface. Similarly, the same $38 \mathrm{~mm}$

193 inclusion may appear with a different size and shape within the reconstruction depending on its

194 relative position with respect to the center of the scan. To illustrate this point, the scan

195 corresponding to Figure 4 (b) is discussed. It can be observed from the reconstructions that the

196 reflections from the inclusions are smaller and less circular than the same inclusion reflections in

197 Figure 4(a) and Figure 4(c). It can be observed from the schematic that these inclusions are

198 located close to the edge of the scanned area causing this observed limited aperture effect. This

199 can limit the ability to assess the reconstructions, as it can be difficult to differentiate structural

200 noise from scatterers of interest when the location within the aperture must be taken into account. 


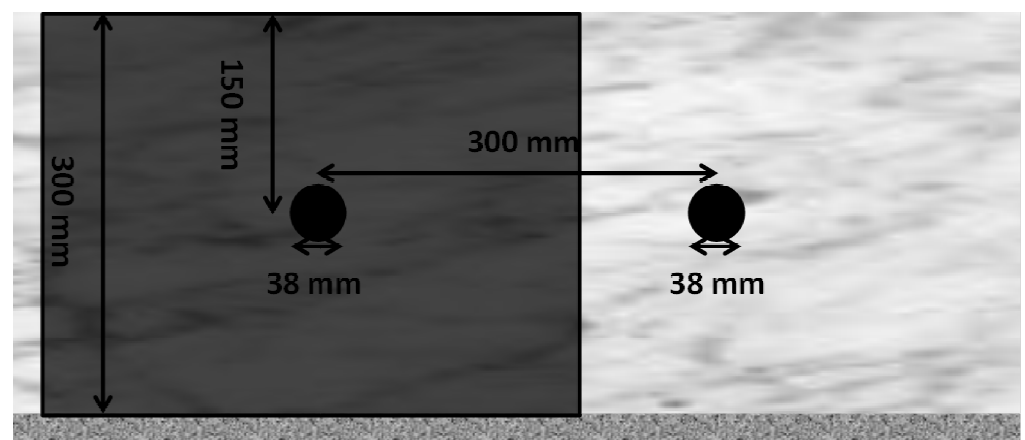

(a)

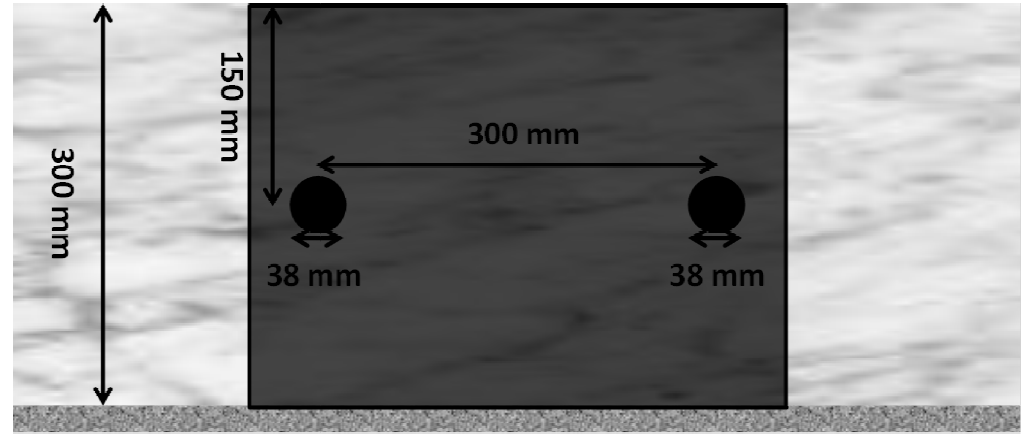

(b)

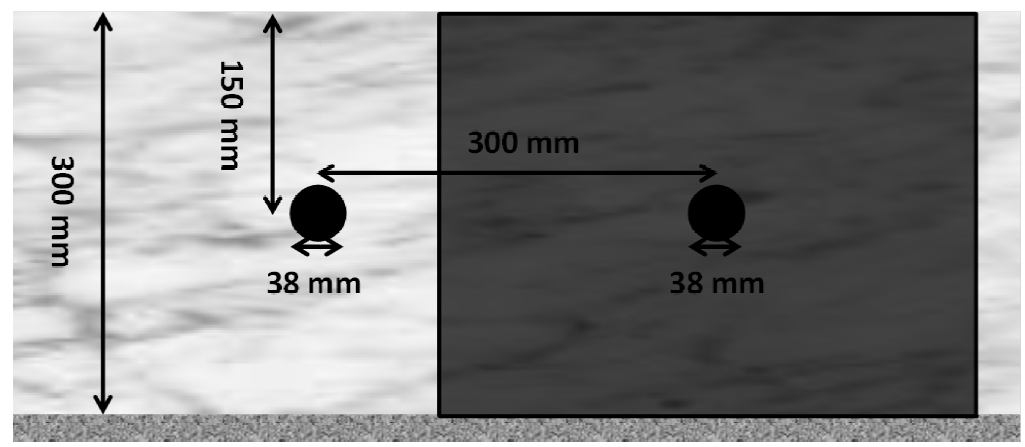

(c)

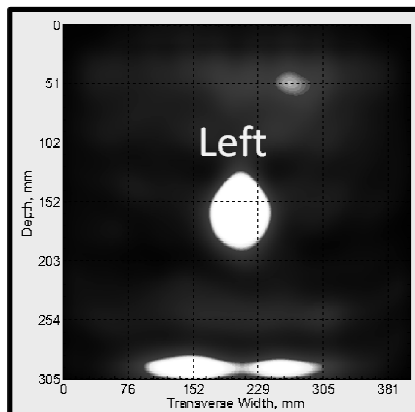

(a)

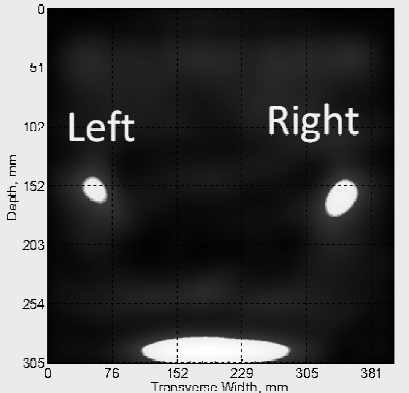

(b)

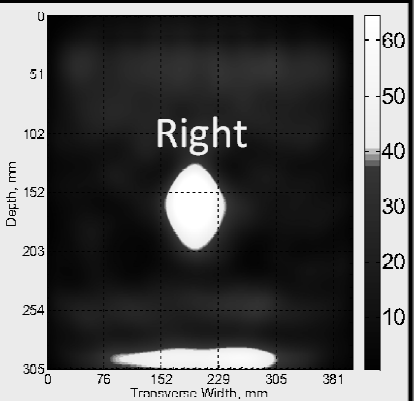

(c)

Figure 4: Three example scans from a set of nine overlapping SAFT-IA B-scans over 2 round 203 metal inclusions. 
205 Figure 5 shows the corresponding SAFT-Pan reconstruction resulting from the 9 overlapping 206 SAFT-IA B-scans taken in $60 \mathrm{~mm}$ target shift factors shown after they have been fused together.

207 By using the SAFT-Pan reconstruction method, the effects caused by limited aperture are

208 mitigated. It can be observed that the resulting panoramic reconstruction is more realistic than 209 the individual SAFT-IA B-scan reconstructions.

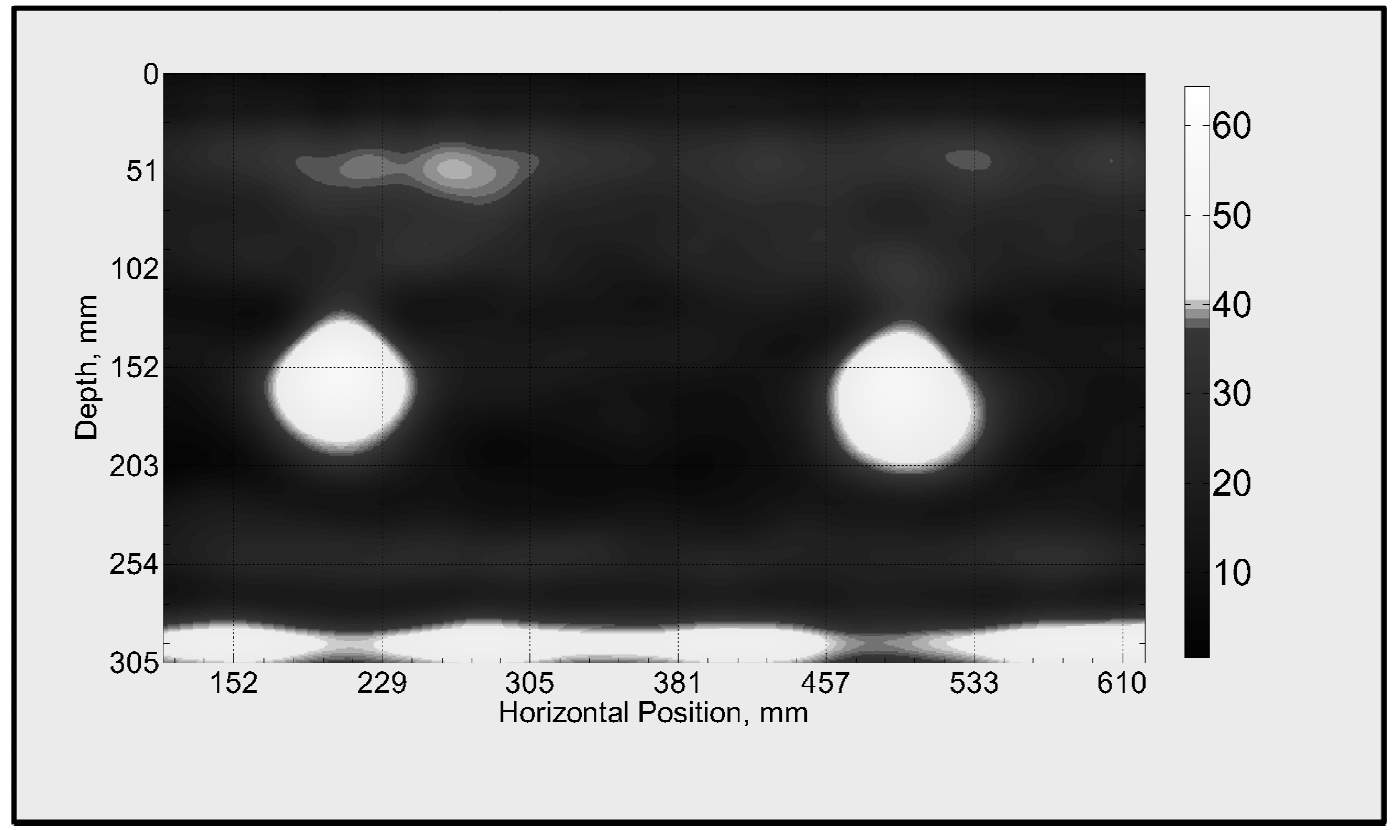

213 However, there are situations where the physical location of each SAFT-IA B-scan is not known

214 precisely. In this case, the SAFT-Pan procedure can introduce significant error. Figure 6 shows

215 an example of a SAFT-Pan reconstruction which combines 9 individual SAFT-IA

216 reconstructions. Unlike in the example in Figure 4, there was some uncertainty in the accuracy

217 of the relative position of the individual scans. When using the target $60 \mathrm{~mm}$ shift factor in

218 SAFT-Pan analysis the reconstruction in the middle exhibits a blurred reflection. This type of

219 reflection may indicate presence of damage or poor consolidation of the concrete around the steel

220 reinforcement, but may also indicate an error in the measurement placement. 


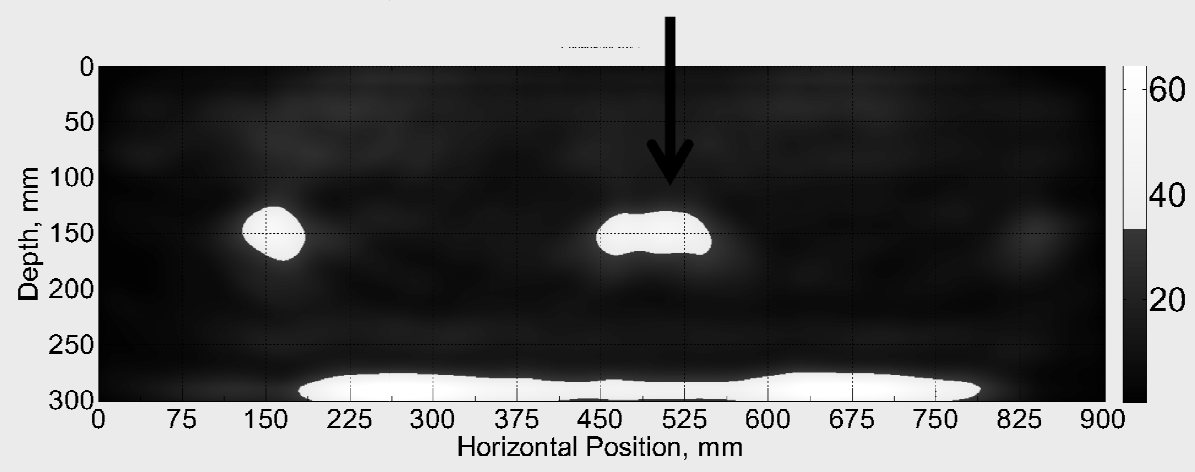

Figure 6: Example SAFT-Pan indicating potential scan placement inaccuracy.

223 A possible approach to resolving this ambiguity is to mitigate scan placement error through the

224 use of a robotic system with dense measurement grids. These types of systems have been

225 developed to allow for precise measurement grids that provide reconstructions of larger areas by

226 stacking individually processed ultrasonic scans [40]. There have been multiple systems

227 developed to accomplish these types of measurements [41-43]. However, the drawbacks of these

228 systems include high cost as well as low flexibility and productivity.

\section{$230 \quad$ 2.4 SAFT Enhanced Panoramic}

231 To address the problem of imprecise measurement locations, an iterative procedure for enhanced

232 panoramic reconstruction is proposed. Rather than assuming precise knowledge of the relative

233 shift between scans, the shift factor for placement of each individual scan is assumed to be

234 within a certain range. This procedure incorporates a similarity of overlapping regions to

235 determine the placement of each scan. It is based on the concept that inclusions and defects

236 within the region of interest should result in similar relative reflectivity, regardless of the

237 location of the scan, assuming the effect of limited aperture is taken into account.

239 First, each SAFT-IA B-scan is numbered according to increasing coordinate in the horizontal

240 direction. Then, the individual SAFT-IA B-scans are added sequentially a panoramic

241 reconstruction. Denote the panoramic reconstruction after the m-th SAFT-IA B-scan is added as

$242[\widehat{0}]^{\text {EPAN,m }}$ and the number of columns in this reconstruction as $\mathrm{W}^{\mathrm{EPAN}, \mathrm{m}}$. The increment of

243 adjacent positions, $\Delta \mathrm{S}$, is assumed to be within a certain range defined by equation 10 : 
247 where $\mathrm{l}_{1}$ and $\mathrm{l}_{2}$ are integers and $\Delta \mathrm{x}$ is the difference in horizontal position between two adjacent 248 columns in the reconstruction.

250 The difference in the adjacent positions of scans $m$ and $m+1$ can be expressed in terms of 251 number of additional step increments, $\mathrm{l}$. For each $\mathrm{\iota}$ within the range $\left[\mathrm{l}_{1}, \mathrm{l}_{2}\right]$ a similarity between 252 portions of the overlapping regions within $[\widehat{0}]^{\mathrm{EPAN}, \mathrm{m}}$ and $[\widehat{\mathrm{O}}]^{\mathrm{IA}, \mathrm{m}+1}$ is determined. To account 253 for the effect of limited aperture, the first $\mathrm{W}_{1}$ columns of $[\widehat{\mathrm{O}}]^{\mathrm{IA}, \mathrm{m}+1}$ and last $\mathrm{W}_{1}$ columns of $254[\widehat{0}]^{\text {EPAN,m }}$ are not considered in determining similarity. In many cases, the stability of the 255 process is improved if only a portion of the reconstruction in the vertical direction $\left[D_{1}, D_{2}\right]$ is 256 included in the comparison. Figure 7 illustrates the process of determining overlapping regions 257 used in the similarity analysis.

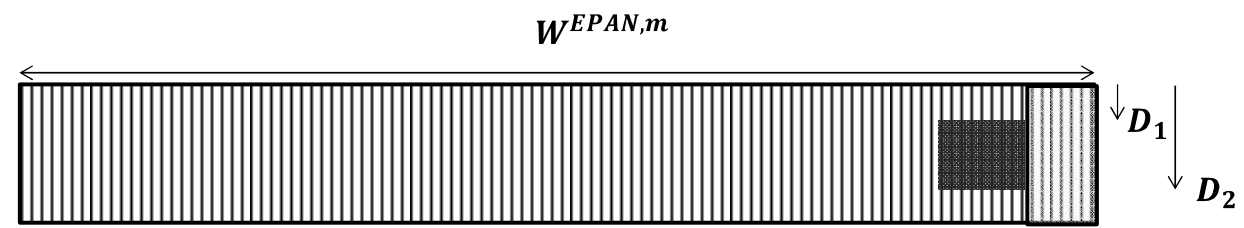

(a) $[\widehat{o}]^{E P A N, m}$
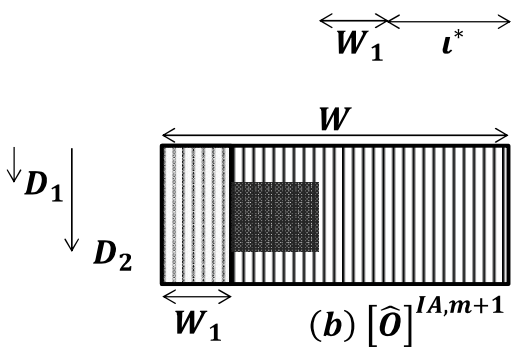

$W^{E P A N, m+1}$

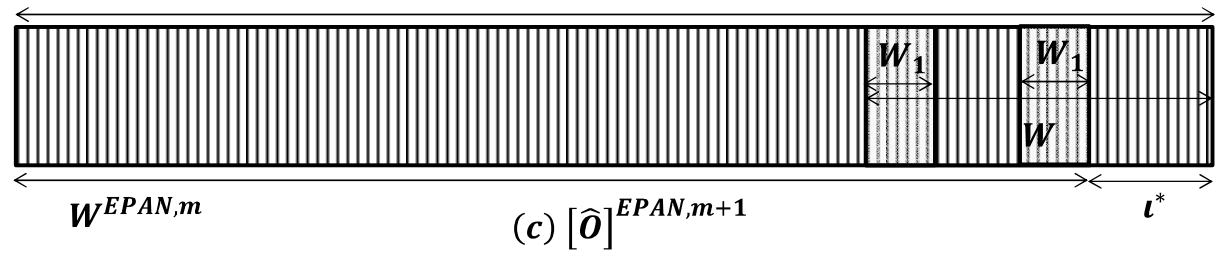

260 Figure 7: Determination of overlapping regions between the reconstructions and determination of 261 the next panoramic reconstruction. 
263 The degree of similarity of the overlapping regions, H(l), is determined based on Pearson's

264 correlation as follows [44]:

265

266

$\mathrm{H}(\mathrm{l})=\frac{\sum_{\mathrm{i}=\mathrm{a}}^{b} \sum_{\mathrm{k}=\mathrm{D}_{1}}^{\mathrm{D}_{2}}\left(\widehat{\mathrm{o}}_{c, k}^{\mathrm{EPAN}, \mathrm{m}}-\widehat{\mathrm{o}}_{\text {mean }}^{\mathrm{EPAN}, \mathrm{m}}\right)\left(\widehat{\mathrm{o}}_{\mathrm{i}, \mathrm{k}}^{\mathrm{m}+1}-\widehat{\mathrm{o}}_{\text {mean }}^{\mathrm{m}+1}\right)}{\sum_{\mathrm{i}=\mathrm{a}}^{\mathrm{b}} \sum_{\mathrm{k}=\mathrm{D}_{1}}^{\mathrm{D}_{2}}\left(\widehat{\mathrm{o}}_{\mathrm{c}, \mathrm{k}}^{\mathrm{EPN}, \mathrm{m}}-\widehat{\mathrm{o}}_{\text {mean }}^{\mathrm{EPAN}, \mathrm{m}}\right)^{2} \sum_{\mathrm{i}=\mathrm{a}}^{\mathrm{b}} \sum_{\mathrm{k}=\mathrm{D}_{1}}^{\mathrm{D}_{2}}\left(\widehat{\mathrm{o}}_{\mathrm{i}, \mathrm{k}}^{\mathrm{m}+1}-\widehat{\mathrm{o}}_{\text {mean }}^{\mathrm{m}+1}\right)^{2}}$

267 where

$\hat{\mathrm{o}}_{\text {mean }}^{\text {EPAN } \mathrm{m}}=\frac{\sum_{\mathrm{i}=\mathrm{g}}^{f} \sum_{\mathrm{k}=\mathrm{D}_{1}}^{\mathrm{D}_{2}} \hat{\mathrm{o}}_{\mathrm{i}, \mathrm{k}}^{\mathrm{EPAN}, \mathrm{m}}}{\left(\mathrm{W}-2 \mathrm{~W}_{1}-\mathrm{l}\right)\left(\mathrm{D}_{2}-\mathrm{D}_{1}+1\right)} ; \quad \hat{\mathrm{o}}_{\text {mean }}^{\mathrm{m}+1}=\frac{\sum_{\mathrm{i}=\mathrm{a}}^{\mathrm{b}} \sum_{\mathrm{k}=\mathrm{D}_{1}}^{\mathrm{D}_{2}} \hat{\mathrm{o}}_{\mathrm{i}, \mathrm{k}}^{\mathrm{m}+1}}{\left(\mathrm{~W}-2 \mathrm{~W}_{1}-\mathrm{l}\right)\left(\mathrm{D}_{2}-\mathrm{D}_{1}+1\right)}$

268

$\mathrm{a}=\mathrm{W}_{1}+1 ; \mathrm{b}=\mathrm{W}-\mathrm{W}_{1}-\mathrm{l} ; c=\mathrm{W}^{\mathrm{EPAN}, \mathrm{m}}-\mathrm{W}+\mathrm{l}+\mathrm{I}$;

269

$\mathrm{f}=\mathrm{W}^{\mathrm{EPAN}, \mathrm{m}}-\mathrm{W}_{1} ; \mathrm{g}=\mathrm{W}^{\mathrm{EPAN}, \mathrm{m}}-\mathrm{W}+\mathrm{\imath}+\mathrm{W}_{1}+1 ;$

270

271 The $\mathrm{t}$ that results in the maximum value of function $\mathrm{H}(\mathrm{l})$ on the interval $\left[\mathrm{l}_{1}, \mathrm{l}_{2}\right]$ is denoted as the

272 optimal shift factor, $\mathrm{L}^{*}$. The next SAFT-EPan reconstruction, $[\widehat{\mathrm{O}}]^{\mathrm{EPAN}, \mathrm{m}+1}$, is defined as follows:

273

274

$\widehat{\mathrm{O}}_{\mathrm{i}, \mathrm{k}}^{\mathrm{EPAN}, \mathrm{m}+1}=\widehat{\mathrm{O}}_{\mathrm{i}, \mathrm{k}}^{\mathrm{EPAN}, \mathrm{m}}$ for $\mathrm{i}<\mathrm{W}^{\mathrm{EPAN}, \mathrm{m}}-\mathrm{W}+\mathrm{i}^{*}+\mathrm{W}_{1}$

$275 \widehat{\mathrm{O}}_{\mathrm{i}, \mathrm{k}}^{\mathrm{EPAN}, \mathrm{m}+1}=\max \left(\widehat{\mathrm{O}}_{\mathrm{i}, \mathrm{k}}^{\mathrm{EPAN}, \mathrm{m}}, \widehat{\mathrm{O}}_{\mathrm{i}-\mathrm{W}^{\mathrm{EPAN}, \mathrm{m}}+\mathrm{W}-\mathrm{l}^{*}, \mathrm{k}}^{\mathrm{m}+1}\right)$

276 for $\mathrm{W}^{\mathrm{EPAN}, \mathrm{m}}-\mathrm{W}+\mathrm{i}^{*}+\mathrm{W}_{1} \leq \mathrm{i} \leq \mathrm{W}^{\mathrm{EPAN}, \mathrm{m}}$

277 and

$278 \widehat{\mathrm{O}}_{\mathrm{i}, \mathrm{k}}^{\mathrm{EPAN}, \mathrm{m}+1}=\widehat{\mathrm{O}}_{\mathrm{i}-\mathrm{W}^{\mathrm{EPAN}, \mathrm{m}}+\mathrm{W}-\mathrm{L}^{*}, \mathrm{k}}^{\mathrm{m}+1}$

279 for $\mathrm{W}^{\mathrm{EPAN}, \mathrm{m}}<i \leq \mathrm{W}^{\mathrm{EPAN}, \mathrm{m}+1}$

280

281 where, $\mathrm{W}^{\mathrm{EPAN}, \mathrm{m}+1}$ is the width of the new SAFT-EPan as defined:

$282 \mathrm{~W}^{\mathrm{EPAN}, \mathrm{m}+1}=\mathrm{W}^{\mathrm{EPAN}, \mathrm{m}}+\mathrm{l}^{*}$

283 Each subsequent reconstruction, $[\widehat{\mathrm{O}}]^{\mathrm{EPAN}, \mathrm{m}+1}$, is obtained from addition of $[\widehat{\mathrm{O}}]^{\mathrm{EPAN}, \mathrm{m}}$ and the

284 next SAFT-IA B-scan, $[\widehat{0}]^{\mathrm{IA}, \mathrm{m}+1}$. The additional number of columns in the new reconstruction,

$285 \mathrm{~L}^{*}$, is determined by comparing the similarity between portions of the overlapping regions within

$286[\widehat{\mathrm{O}}]^{\mathrm{EPAN}, \mathrm{m}}$ and $[\widehat{\mathrm{O}}]^{\mathrm{IA}, \mathrm{m}+1}$. The additional columns, $\mathrm{\iota}^{*}$, are chosen from within the range of

287 potential shift factors $\left[\mathrm{l}_{1}, \mathrm{l}_{2}\right]$. 


\section{RESULTS AND DISCUSSION}

\section{$291 \quad 3.1$ Illustrative Example}

292 This section demonstrates how the procedure described in the SAFT-Enhanced Panoramic 293 section is used to determine the optimal shift factor, $\iota^{*}$, when fusing multiple overlapping scans 294 into an extended reconstruction. Figure 8 shows artificially generated reconstructions where an 295 identical square inclusion exists in both the current SAFT-EPan reconstruction [0ิ0] $]^{\text {EAAN,m }}$ and 296 the next SAFT-IA B-scan, [0ำ $]^{\mathrm{IA}, \mathrm{m}+1}$, which is shifted by $50 \mathrm{~mm}$. Figure $8 \mathrm{c}$ shows Pearson's 297 similarity correlation function, $\mathrm{H}(\mathrm{l})$, where the shift factor is assumed to be somewhere between $29830 \mathrm{~mm}$ to $70 \mathrm{~mm}$ for the corresponding overlapping regions within this interval taken with a step 299 of $0.8 \mathrm{~mm}$. As can be observed from Figure 8c, the maximum similarity value of $H(\iota)=1$, 300 indicating a perfect correlation, corresponds to the actual shift factor between measurements.

302 Although a perfect correlation is not realistic to expect from field data, use of this type of 303 analysis often result in significant similarity at the determined shift factor, typically greater than 3040.9 , for overlapping regions when a strong feature is located within the ROI. Examples of this 305 type of analysis conducted on field data taken on a concrete slab are given below. 


\section{(a)}
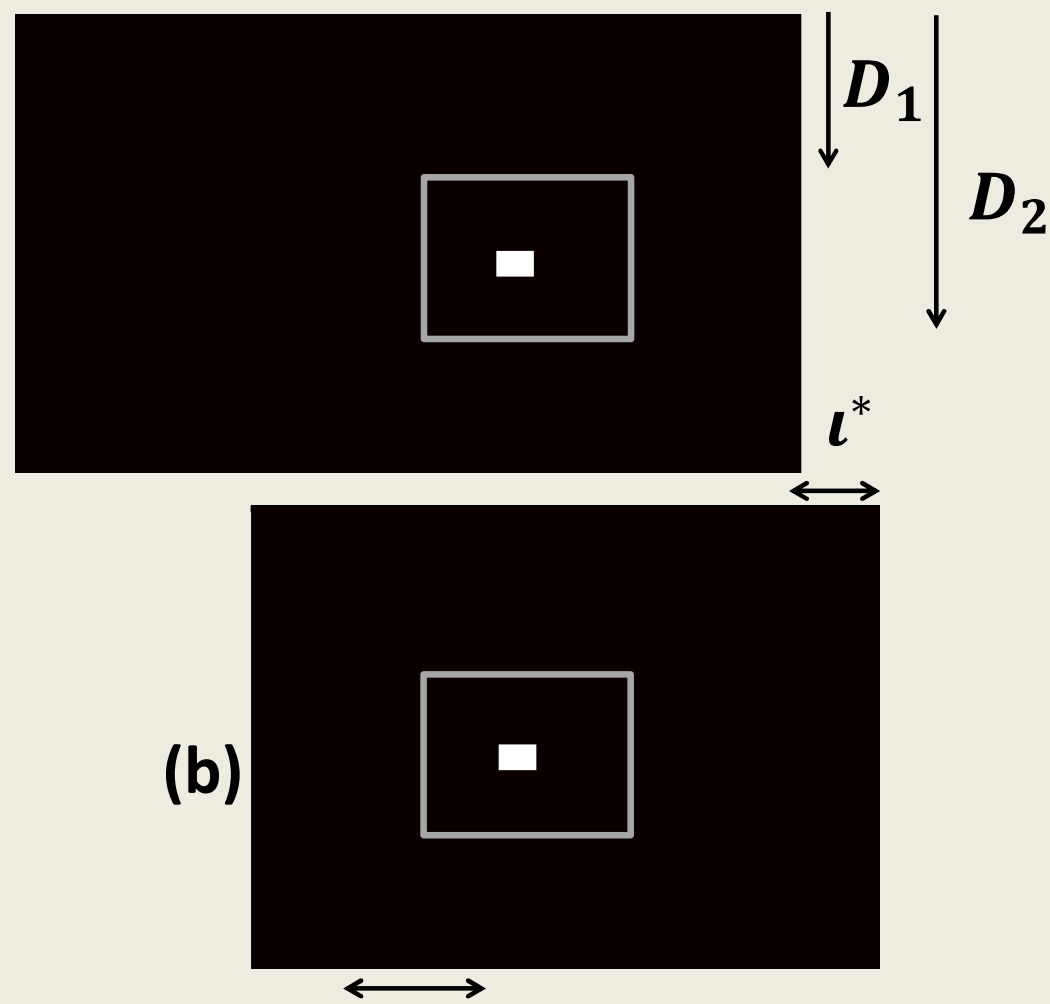

\section{$W_{1}$}

Determination of Optimal Shift Factor

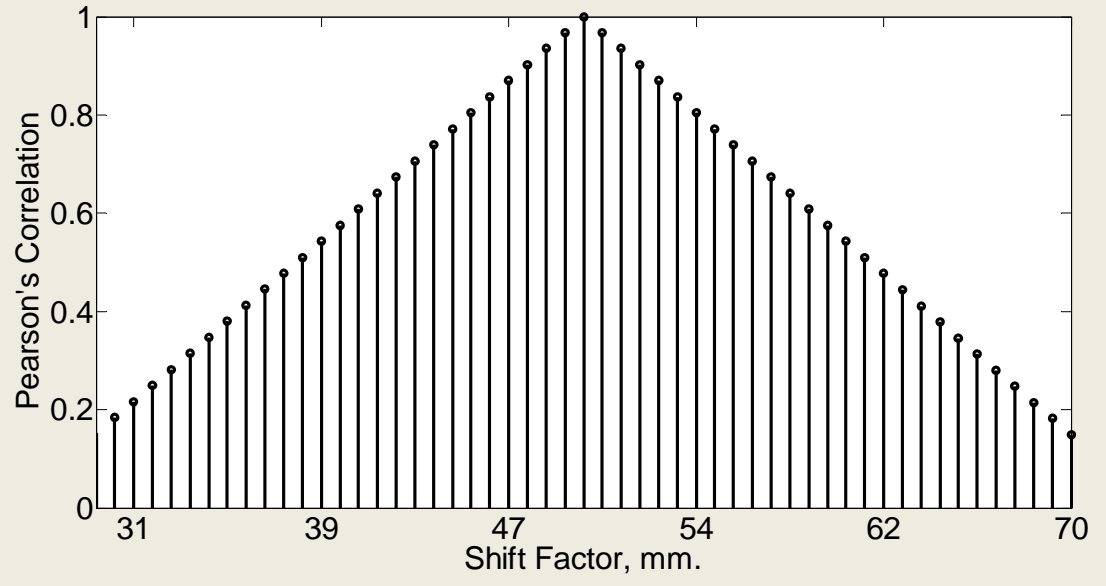

(c)

Figure 8. Shift factor determination for artificially generated reconstructions (a) m-th SAFT- 


\section{$312 \quad 3.2$ Field Trials}

313 The SAFT schemes proposed above have been utilized on several full-scale in-situ testing

314 locations to provide practical non-destructive evaluation information when interrogating concrete

315 structures. This includes location of inclusions and determination of internal flaws such as cracks

316 or defects.

\section{$317 \quad 3.2 .1$ Inclusion Characterization}

318 Implementation of the SAFT-EPan scheme has shown to be especially useful for applications

319 where there is a designed inclusion located within multiple overlapping scans. One such

320 example was introduced in Figure 5 where 9 overlapping measurements were taken on a $300 \mathrm{~mm}$

321 thick portland cement concrete (PCC) slab with two 38-mm diameter steel reinforcements at the

322 mid-depth of the slab. Figure 9 shows example determination of the shift factor for placement of

323 the of the 6th SAFT-IA reconstruction where one of the steel reinforcements exists in both the

324 current reconstruction (see Figure 9a), $[\widehat{0}]^{\text {EPAN,m }}$, and the next individual SAFT-IA B-scan (see

325 Figure $9 \mathrm{~b}),[\widehat{\mathrm{o}}]^{\mathrm{IA}, \mathrm{m}+1}$, to be placed. The results of Pearson's similarity correlation function, $326 \mathrm{H}(\mathrm{l})$, for the shift factors within interval $[30 \mathrm{~mm}, 70 \mathrm{~mm}]$ are shown in Figure $9 \mathrm{c}$. In this case,

327 the maximum value of Pearson's similarity correlation used to determine the shift factor is not an

328 exact similarity of 1 . However, the highest reflectivity location is significant at over $95 \%$ at

329 slightly less than $50 \mathrm{~mm}$, which was over $10 \mathrm{~mm}$ less than the target shift factor. Correction of

330 the shift factor using SAFT-EPan for cases like this can improve resolution of the resulting

331 panoramic reconstruction and have a significant impact on the interpretation. 


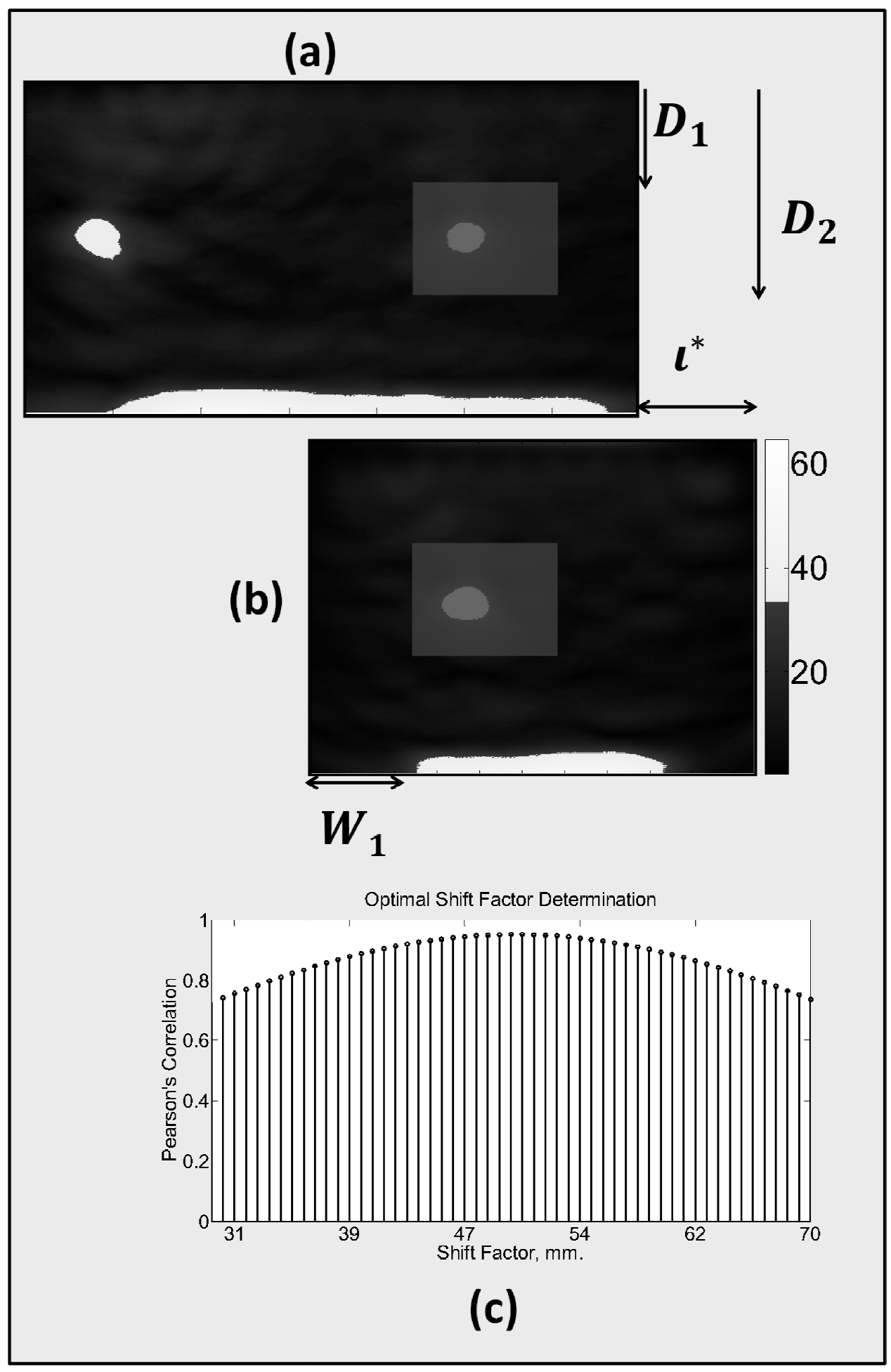

Figure 9. Shift factor determination for in-situ reconstructions (a) m-th SAFT-EPan

334 reconstruction (b) $m+1$ SAFT I-A reconstruction with an identical inclusion and (c) Pearson's correlation for various shift factors. 
337 Figure 10a shows the SAFT-EPan reconstruction obtained from the same individual SAFT-IA

338 scans from Figure 5. The shift factors were determined by using the highest similarity of

339 overlapping regions using the procedure described in equation 11 resulting in shift factors

340 significantly less than the $60 \mathrm{~mm}$ target shift factors on average. It can be observed that the new

341 shift factors, determined using the enhanced panoramic reconstruction procedure, resulted in

342 focusing of the reflectivity reconstruction in the area of the dowel. This type of focused

343 reflectivity in the reconstruction should be expected at a round steel reinforcement embedded in

344 sound surrounding concrete.

346 A core at the doweled location is also shown in Figure 10b indicating a single dowel with

347 relatively sound surrounding concrete. This validates that the blurred reflectivity in the region of

348 the dowel observed in Figure 5 was caused by the error in the pre-defined $60 \mathrm{~mm}$ shift factors

349 used in the SAFT-Pan reconstruction. This also validates that the SAFT-EPan reconstruction

350 correctly focused the reflectivity to the actual change in acoustic impedance to the region of the

351 embedded dowel. It should be noted that, while the center of gravity of the inclusion reflectivity

352 approximates the inclusion location [15], the diameter of the inclusion representation depends on

353 the selected threshold. It can be observed that the diameter of the reconstruction inclusion for

354 the chosen threshold is similar, but slightly larger than the actual inclusion represented by the

355 black circle on the reconstruction. Determination of the absolute diameter of an inclusion

356 without any prior information is not feasible using the method described in this study. However,

357 by accounting for the limited aperture effect on reflectivity in the extended reconstructions,

358 comparison of relative sizes of inclusions can be conducted. 


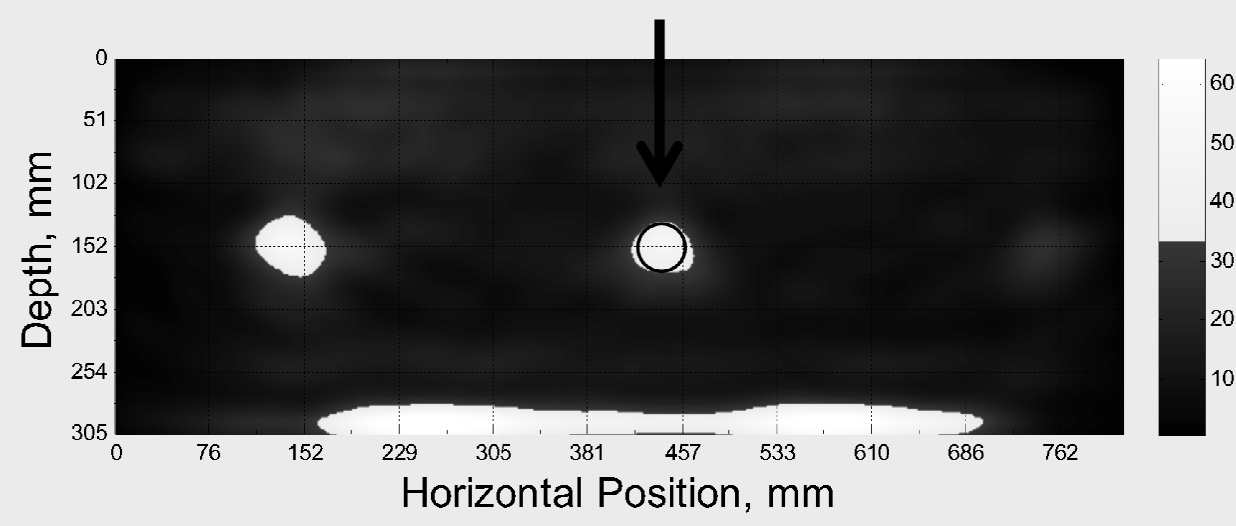

(a)

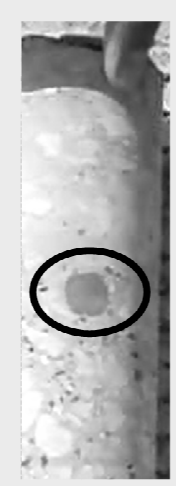

(b)

Figure 10. (a) SAFT-EPan reconstruction allowing for $+/-30 \mathrm{~mm}$ error and (b) subsequent forensics at the example overlapping scans location.

364 In addition to locating and characterizing inclusions such as reinforcements, SAFT-EPan

365 reconstructions can be useful for identifying flaws that are thin in the lateral dimension such as

366 vertical cracks in concrete. To validate the ability of the proposed method, measurements were

367 taken on a specimen where controlled vertical cracks were fabricated by placing $254 \mathrm{~mm}$ by 76

$368 \mathrm{~mm}$ triangular wedges into the backside of a $254 \mathrm{~mm}$ concrete wall and removing after the initial

369 set. The wedges included in this study were a $1.5 \mathrm{~mm}$ thick steel sheet (CR1) and $3 \mathrm{~mm}$ thick

370 polycarbonate sheet (CR2). These defects were fabricated by Hiltunen et al. [43] and tested on

371 the front (uncracked) side by the authors as part of a study by Clayton et al. [17]. Figure 11

372 shows a schematic of the cross section below the scans analyzed as part of this paper. The

373 portion of the triangular wedge associated with the measurements in this study were $5 \mathrm{~mm}$ in

374 height from the opposite side surface with respect to where the scans were taken. 


\section{Scanning Surface}

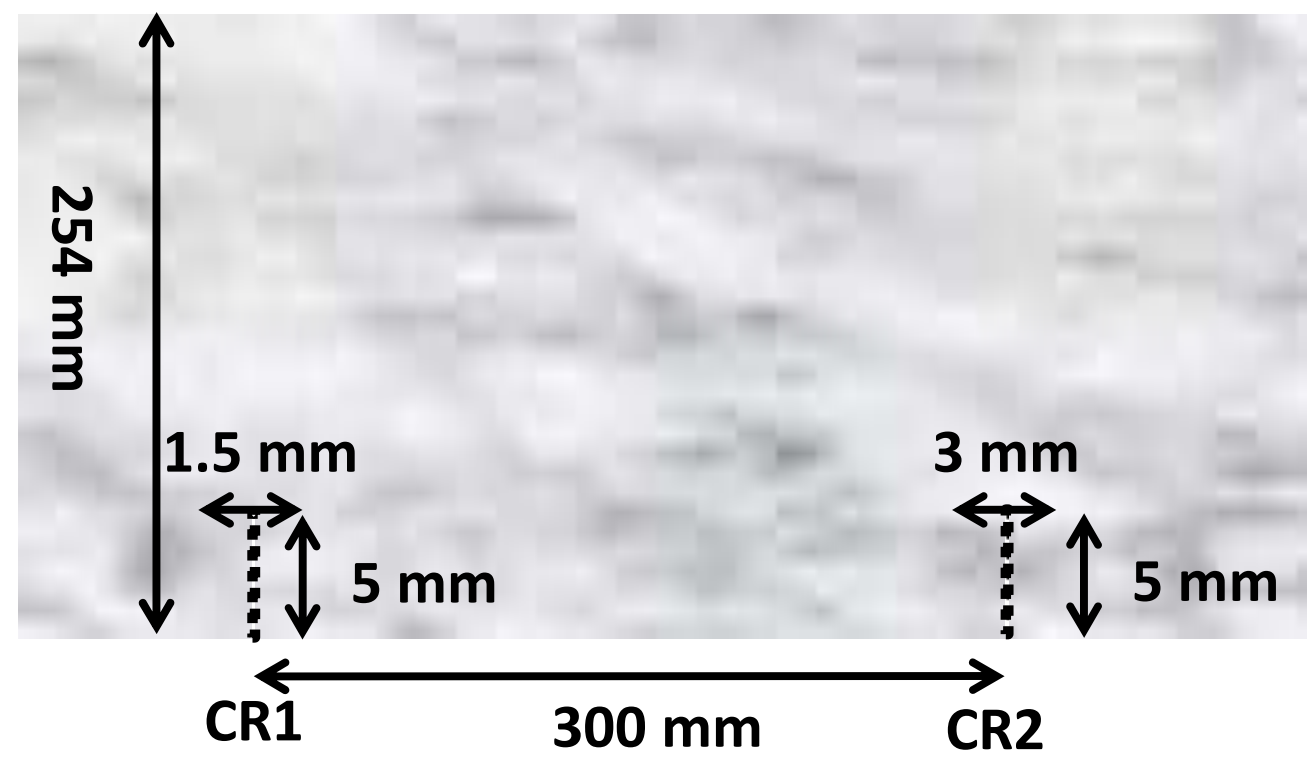

377 Figure 11: Concrete wall specimen with no visible distress on the front side and two simulated cracks on the back side.

380 Figure 12 a shows the location of the backside crack, CR1, in relation to the two individual

381 SAFT-IA reconstructions adjacent to the vertical crack, as indicated by the arrows. The SAFT-

382 IA reconstructions do not give a clear indication of any discontinuity since it is difficult to

383 resolve shadowing from the crack versus reduction in reflectivity due to limited aperture toward 384 the edges. 


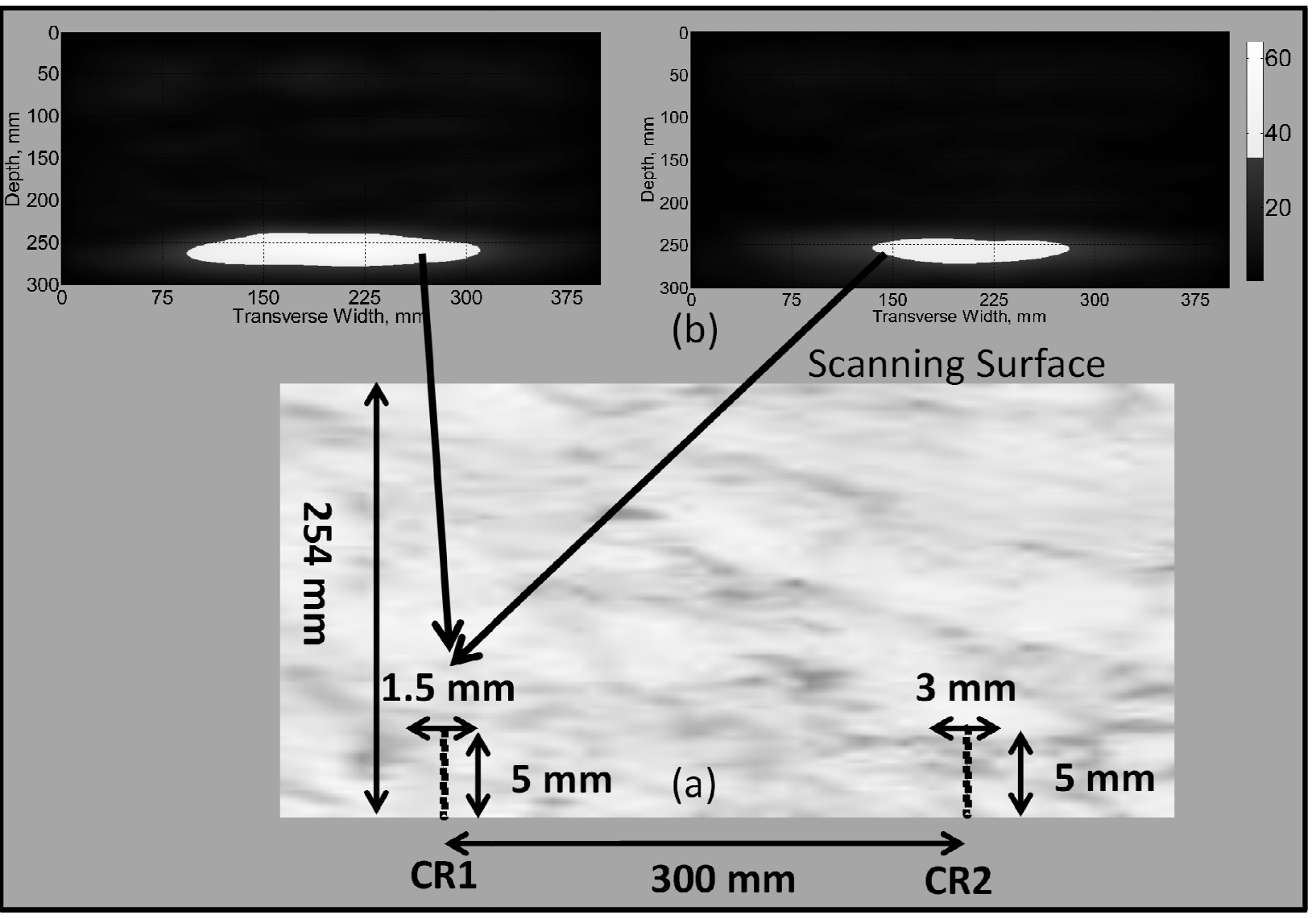

Figure 12: SAFT-IA reconstructions at the CR1 location during vertical scanning.

390 Figure 13 shows analysis of SAFT-EPan reconstruction results from eleven overlapping scans

391 with $102 \mathrm{~mm}$ shift factors taken on top of the area with cracks on the backside. As can be

392 observed from Figure 13, there is no direct reflection corresponding to the tip of the crack

393 location. This is typical for laterally thin defects that are perpendicular to the measurement

394 surface. However, the cracks can be detected indirectly by observing the reduction of reflection

395 or "shadowing" [19] at the "backwall" thickness interface of the PCC. It can be observed from

396 Figure $13 \mathrm{~b}$ and $\mathrm{c}$ that there is a reduction in intensity or even a slight discontinuity in the

397 backwall reflection at the crack locations. Figure 13d shows a plot of the relative reflectivity

398 values along the depth associated with the PCC thickness leading up to and away from the CR1

399 crack location. The vertical crack location can be clearly identified by the drop in relative

400 reflectivity. This highlights the importance of using SAFT-EPan reconstructions, where relative

401 reflectivity values can be quantitatively compared within the reconstruction without potential

402 misinterpretations caused by limited aperture. 


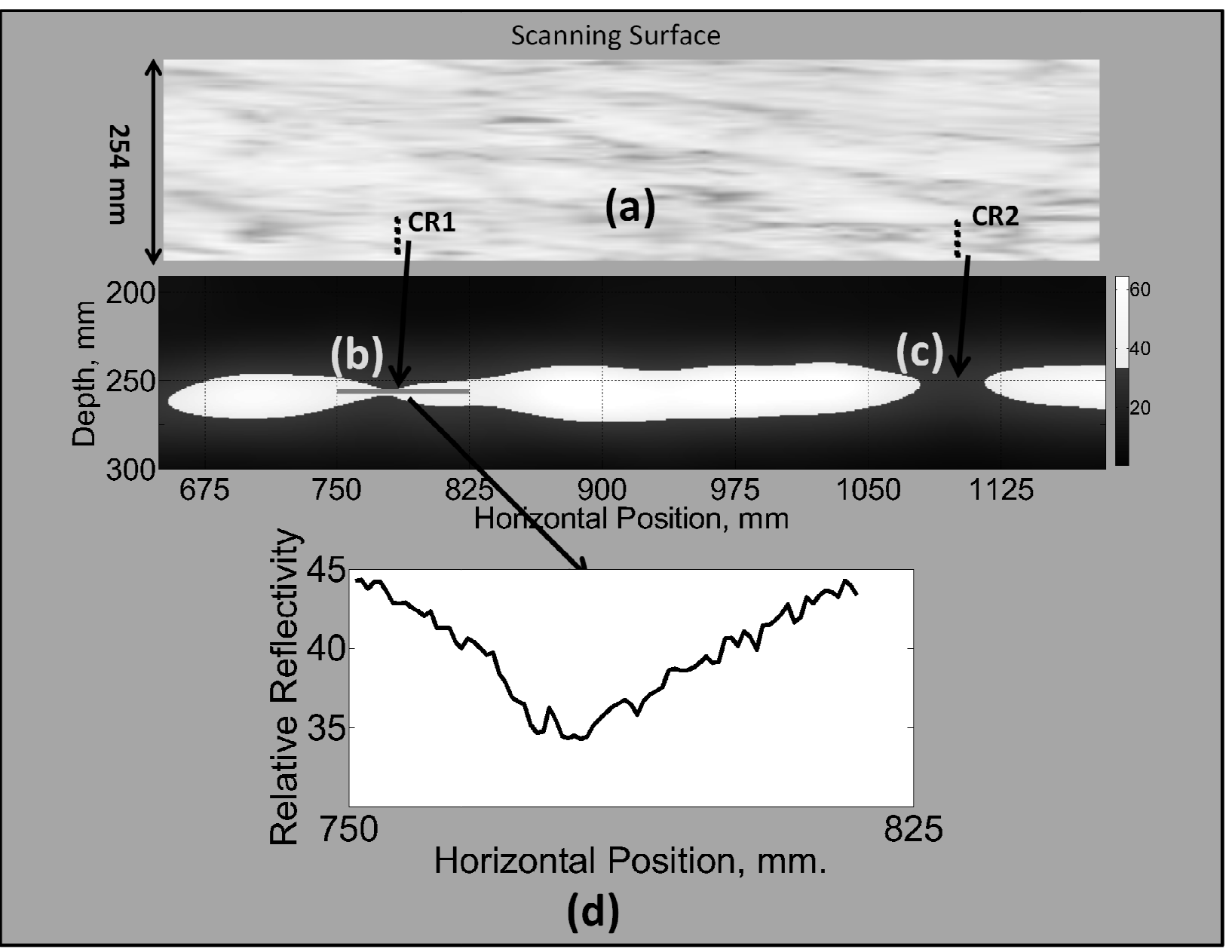

Figure 13: Use of SAFT-EPan and relative reflectivity measures to identify a vertical crack.

\section{CONCLUSIONS}

407 Although SAFT-based migration techniques in conjunction with linear array systems have been

408 used to provide useful nondestructive information on subsurface condition of concrete, the effect

409 of limited aperture has been identified as impedance to quantitative interpretation. The SAFT-

410 EPan reconstruction methodology presented in this paper was demonstrated to address this

411 limitation through generalization of traditional migration methods to handle virtual arrays. The

412 proposed implementation uses quantitative similarity measures of overlapping regions to account

413 for imprecision in adjacent scan measurement placement. This is especially important for

414 situations where robotic precision of scan placement is not feasible. Analysis of full scale 
415 controlled tests on PCC slabs demonstrated improved resolution and reliability for

416 characterization of defects or inclusions.

\section{ACKNOWLEDGEMENTS}

418 Part of the work presented in this paper was conducted for Oak Ridge National Laboratory (UT-

419 Battelle, LLC), acting under contract DE-AC05-00OR22725 with the U.S. Department of

420 Energy. Dr. Chris Ferraro from the University of Florida was led the specimen construction

421 efforts and coordinated testing of the simulated crack used in this paper.

\section{REFERENCES}

423 1. McCann, D. M., and M. C. Forde. "Review of NDT methods in the assessment of

$424 \quad$ concrete and masonry structures." NDT \& E International 34.2 (2001): 71-84.

$425 \quad \underline{\text { doi:10.1016/S0963-8695(00)00032-3 }}$

426 2. Carino, N. J. "The impact-echo method: an overview." Proceedings of the 2001

427 Structures Congress \& Exposition, May, (2001): 21-23. Link:

428 http://fire.nist.gov/bfrlpubs/build01/PDF/b01005.pdf?origin=publication_detail

3. Gibson, A. and Popovics J.S. "Lamb Wave Basis for Impact-Echo Method Analysis." Journal of Engineering Mechanics. American Society of Civil Engineering. Volume 131 Issue 4. (2005). Permalink: http://dx.doi.org/10.1061/(ASCE)07339399(2005)131:4(438)

4. Baggens, Oskar, and Nils Rydén. "Systematic errors in impact-echo thickness estimation due to near field effects." NDT \& E International (2014). doi:10.1016/j.ndteint.2014.09.003

5. Buckley, Joe, and Hanspeter Loertscher. "Frequency considerations in air-coupled ultrasonic inspection." BINDT Conference. Insight 41.11 (1999): 696-9. Link: http://joe.buckley.net/papers/BINDT99\%20Airscan.PDF

6. Blum, Frank, Jacek Jarzynski, and Laurence J. Jacobs. "A focused two-dimensional aircoupled ultrasonic array for non-contact generation." NDT \& E International 38.8 (2005): 634-642. doi:10.1016/j.ndteint.2005.03.002 
7. Zhu, J. and Popovics, J. S. "Non-contact imaging for surface-opening cracks in concrete with air-coupled sensors." Materials and Structures. Springer Netherlands Volume 38, Issue 9. (2005): 801-806. DOI: 10.1007/BF02481652

8. Zhu, Jinying, and John S. Popovics. "Imaging concrete structures using air-coupled impact-echo." Journal of engineering mechanics 133.6 (2007): 628-640. Permalink: http://dx.doi.org/10.1061/(ASCE)0733-9399(2007)133:6(628)

9. Chimenti, D E, "Review of air-coupled ultrasonic materials characterization." Ultrasonics 54.7 (2014):1804-1816. doi:10.1016/j.ultras.2014.02.006

10. Kim, G., Chi-Won, I., Jin-Yeon, K., Kurtis, K.E., and Jacobs, L.J. "Air-coupled detection of nonlinear Rayleigh surface waves in concrete-Application to microcracking detection." NDT \& E International 67 (2014): 64-70. doi:10.1016/j.ndteint.2014.07.004

11. Shevaldykin, V. G., Samokrutov A. A., and Kozlov V. N., "Ultrasonic Low-Frequency Transducers with Dry Dot Contact and Their Applications for Evaluation of Concrete Structures.” IEEE Ultrasonics Symposium Proceedings 1 \& 2, 793-798. (2002). DOI: 10.1109/ULTSYM.2002.1193518.

12. F. Schubert and B. Kohler. "Ten lectures on impact-echo", J. Nondestr. Eval., 27, (2008): 5-21. DOI: 10.1007/s10921-008-0036-2

13. Hoegh, K., Worel, B., Yu T., and Khazanovich, L. "Detection of Subsurface Joint Deterioration" Transportation Research Record: Journal of the Transportation Research Board. Volume 2367. Issue 1 (2013): 3-12. DOI: 10.3141/2367-01 Link: http://trb.metapress.com/index/U5246303832JH385.pdf

14. Krause M, Mielentz F, Milman B, Muller W, Schmitz V, Wiggenhauser H. "Ultrasonic imaging of concrete members using an array system." NDT \& E International ; 34 (2001):403-8. doi:10.1016/S0963-8695(01)00007-X

15. Hoegh, K., Yu T., and L. Khazanovich. "Ultrasonic Tomography Technique for Evaluation of Concrete Pavements," Transportation Research Record: Journal of the Transportation Research Board. Volume 2232 (2011): 85-94. DOI: 10.3141/2232-09 link: http://trb.metapress.com/index/M308772U630817W3.pdf

16. Hoegh, K., Khazanovich, L., Maser, K. R. \& Tran, N “Evaluation of Ultrasonic Technique for Detecting Delamination in Asphalt Pavements." Transportation Research 
Record: Journal of the Transportation Research Board. Volume 2306 (2012): 105-110. DOI: 10.3141/2306-12 link: http://trb.metapress.com/content/8912621q4p36x3h4/

17. Clayton, D.A., Smith, C.M., Ferraro, C.C., Nelson, J., Khazanovich, L., Hoegh, K., Chintakunta, S., Popovics, J., "Evaluation of Ultrasonic Techniques on Concrete Structures." No. ORNL/TM-2013/430. Oak Ridge National Laboratory (2013). DOI: $\underline{10.2172 / 1095161}$

18. Clayton, D.A. and Smith, C.M. "Comparative testing of nondestructive examination techniques for concrete structures ", Proc. SPIE 9063, Nondestructive Characterization for Composite Materials, Aerospace Engineering, Civil Infrastructure, and Homeland Security 2014, 90631G (March 9, 2014); doi:10.1117/12.2045138; http://dx.doi.org/10.1117/12.2045138

19. Schickert, Martin. "Progress in ultrasonic imaging of concrete." Materials and Structures 38.9 (2005): 807-815. DOI: 10.1007/BF02481653

20. Hoegh, K. and L. Khazanovich "Concrete Pavement Joint Diagnostics Using Ultrasonic Tomography," Transportation Research Record: Journal of the Transportation Research Board. Volume 2305 (2012): p.54-61. DOI: 10.3141/2305-06 link: http://trb.metapress.com/index/2V8010452NP07K06.pdf

21. Schabowicz K, Suvorov V. "Nondestructive Testing of a Bottom Surface and Construction of its Profile by Ultrasonic Tomography" Russ J Nondestruct Test; 50(2) (2014):109-19. DOI: 10.1134/S1061830914020089

22. Mayer, K., Langenberg, K. J., Krause, M., Milmann, B. \& Mielentz, F. “Characterization of reflector types by phase-sensitive ultrasonic data processing and imaging." Journal of Nondestructive Evaluation, 27, (2008): 35-45. DOI: 10.1007/s10921-008-0035-3

23. Shokouhi, Parisa, Julia Wolf, and Herbert Wiggenhauser. "Detection of Delamination in Concrete Bridge Decks by Joint Amplitude and Phase Analysis of Ultrasonic Array Measurements." Journal of Bridge Engineering 19.3 (2013). Permalink: http://dx.doi.org/10.1061/(ASCE)BE.1943-5592.0000513 24. Schabowicz K. "Ultrasonic tomography - the latest nondestructive technique for testing concrete members - description, test methodology, application example." Arch Civ Mech Eng;14(2) (2014): 295-303. doi:10.1016/j.acme.2013.10.006 
25. Hoegh, K. and L. Khazanovich. "Correlation Analysis of 2D Tomographic Images for Flaw Detection in Pavements," Journal of Testing and Evaluation. American Society for Testing and Materials Paper ID: JTE103765, Volume 40, Issue 2. (2012): 9 pages. DOI: 10.1520/JTE103765 link: http://www.astm.org/DIGITAL_LIBRARY/JOURNALS/TESTEVAL/PAGES/JTE1037 $\underline{65 . h t m}$

26. Krautkrämer, Josef, and Herbert Krautkrämer. "Ultrasonic testing of materials. 4th fully revised edition." Chapter 2. Page 33 Figure 2.16. (1990).

27. Ganguli A., Rappaport, C.M., Abramo D., Wadia-Fascetti, S. "Synthetic aperture imaging for flaw detection in a concrete medium" NDT\&E International 45 (2012) 7990. doi:10.1016/j.ndteint.2011.09.004

28. Langenberg, K. J., Berger, M., Kreutter Th., Mayer, K., and Schmitz, V., "Synthetic aperture focusing technique signal processing." NDT International 19.3 (1986): 177-189. doi:10.1016/0308-9126(86)90107-0

29. Spies, M., Rieder, H., "Synthetic aperture focusing of ultrasonic inspection data to enhance the probability of detection of defects in strongly attenuating materials." NDT \& E International 43.5 (2010): 425-431. doi:10.1016/j.ndteint.2010.04.002

30. Spies, M., Rieder, H., Dillhöfer, A., Schmitz, V., Müller, W., "Synthetic Aperture Focusing and Time-of-Flight Diffraction Ultrasonic Imaging_Past and Present." $J$ Nondestruct Eval (2012) 31:310-323 DOI: 10.1007/s10921-012-0150-Z

31. Schickert, M., Krause, M. \& Müller, W. (2003). "Ultrasonic imaging of concrete elements using reconstruction by synthetic aperture focusing technique." Journal of Materials in Civil Engineering, 15, 235-246.

Permalink: http://dx.doi.org/10.1061/(ASCE)0899-1561(2003)15:3(235)

32. Tong, J.H., Chiu, C.L., and Wang, C.Y. "Improved Synthetic Aperture Focusing Technique by Hilbert-Huang Transform for Imaging Defects Inside a Concrete Structure" IEEE Transactions on Ultrasonics, Ferroelectrics, and Frequency Control, vol. 57, no. 11, November 2010 DOI: 10.1109/TUFFC.2010.1717

33. Tong, J.H., Chiu, C.L., Wang, C.Y., and S.T. Liao. "Influence of rebars on elastic-wavebased synthetic aperture focusing technique images for detecting voids in concrete structures." NDT \& E International 68 (2014): 33-42. doi:10.1016/j.ndteint.2014.08.001 
34. Hoła J, Schabowicz K. "State-of-the-art non-destructive methods for diagnostic testing of building structures - anticipated development trends." Arch Civ Mech Eng; 3; (2010):518. doi:10.1016/S1644-9665(12)60133-2

35. Hoegh, Kyle. Ultrasonic Linear Array Evaluation of Concrete Pavements, Ph.D. Thesis, University of Minnesota, 2013. Permanent link: http://purl.umn.edu/155823

36. Blum F., Physical properties handbook: a guide to the shipboard measurement of physical properties of deep-sea cores. ODP Tech. Note, 26. 1997 Permalink: http://wwwodp.tamu.edu/publications/tnotes/tn26/INDEX.HTM

37. Bamler, R. "A comparison of range-Doppler and wavenumber domain SAR focusing algorithms." Geoscience and Remote Sensing, IEEE Transactions on, 30, (1992):706713. DOI: $\underline{10.1109 / 36.158864}$

38. Huang, N. E. \& Attoh-Okine, N. O. "The Hilbert-Huang transform in engineering," $C R C$. (2005). Link: http://www.crcpress.com/product/isbn/9780849334221

39. Todoran, G., Holonec, R. \& Iakab, C. "Discrete Hilbert Transform. Numeric Algorithms." ACTA Electronica. Mediamira Science Publisher. Volume 49, No. 4. (2008): 485-490. Link: http://ie.utcluj.ro/files/acta/2008/Number4/Paper14_Todoran.pdf

40. Wiggenhauser, H. "Automated NDE of Structures with Combined Methods," Nondestructive Testing of Materials and Structures. RILEM Bookseries Volume 6, (2013):753-760. DOI: 10.1007/978-94-007-0723-8_107

41. Streicher, D., Algernon, D., Wöstmann, J., Behrens, M., \& Wiggenhauser, H.. "Automated NDE of post-tensioned concrete bridges using imaging echo methods." Proceedings of the 9th European Conference on NDT (2006): 25-29. Link: http://212.8.206.21/article/ecndt2006/doc/We.1.3.1.pdf

42. Kohl, C. and D. Streicher. "Results of reconstructed and fused NDT-data measured in the laboratory and on-site at bridges." Cement \& Concrete Composites 28 (2006): 402-413. doi:10.1016/j.cemconcomp.2006.02.005

43. Hiltunen, D.R., Algernon, D, Ferraro, C.C., "Validation of Nondestructive Testing Equipment for Concrete," Florida Department of Transportation Research Center and University of Florida Department of Civil and Coastal Engineering, Gainesville, FL, (2010). Link: http://www.dot.state.fl.us/researchcenter/Completed_Proj/Summary_SMO/FDOT_BD545-80_rpt.pdf 
564 44. Gibbons, J.D., and Chakraborti, S. “Nonparametric statistical inference." Springer Berlin $565 \quad$ Heidelberg, (2011). Link:

566 http://dv.fosjc.unesp.br/ivan/downloads/Livros_de_Estatistica_em_PDF*Gibbons_Nonpa 567 rametric_(2003).pdf

568

569

570 
571 Figure 1: Illustration of the type of data utilized in this paper including a [a] schematic of the 572 measurement setup on a concrete slab including direct and reflection arrival paths and [b]

573 example impulse time history from a transducer pair spaced by $200 \mathrm{~mm}$.

574 Figure 2: Linear array representation.

575 Figure 3. Schematic of the reinforced concrete structure used for analysis.

576 Figure 4: Three example scans from a set of nine overlapping SAFT-IA B-scans over 2 round 577 metal inclusions.

578 Figure 5: SAFT-Pan reconstruction showing the consistent metal inclusions and continuous 579 reflection at the depth of the PCC slab.

580 Figure 6: Example SAFT-Pan indicating potential scan placement inaccuracy.

581 Figure 7: Determination of overlapping regions between the reconstructions and determination of 582 the next panoramic reconstruction.

583 Figure 8. Shift factor determination for artificially generated reconstructions (a) m-th SAFT-

584 EPan reconstruction (b) $m+1$ SAFT I-A reconstruction with an identical inclusion and (c)

585 Pearson's correlation for various shift factors.

586 Figure 9. Shift factor determination for in-situ reconstructions (a) m-th SAFT-EPan

587 reconstruction (b) m+1 SAFT I-A reconstruction with an identical inclusion and (c) Pearson's 588 correlation for various shift factors.

589 Figure 10. (a) SAFT-EPan reconstruction allowing for $+/-30 \mathrm{~mm}$ error and (b) subsequent

590 forensics at the example overlapping scans location.

591 Figure 11: Concrete wall specimen with no visible distress on the front side and two simulated 592 cracks on the back side.

593 Figure 12: SAFT-IA reconstructions at the CR1 location during vertical scanning.

594 Figure 13: Use of SAFT-EPan and relative reflectivity measures to identify a vertical crack. 595 